\title{
XXXIII. Observations on the pharmaceutical and chemical characters of the Peruvian matico
}

\author{
John F. Hodges M.D.
}

To cite this article: John F. Hodges M.D. (1844) XXXIII. Observations on the pharmaceutical and chemical characters of the Peruvian matico , Philosophical Magazine Series 3, 25:165, 202-207, DOI: $10.1080 / 14786444408644971$

To link to this article: http://dx.doi.org/10.1080/14786444408644971

曲 Published online: 30 Apr 2009.

Submit your article to this journal $₫$

Џ Article views: 2

Q View related articles $\square$ 


\section{Dr. Hodges on the Pharmaceutical and Chemical}

The grass oil consists, therefore, of a carburetted hydrogen, having the same composition, $\mathrm{C}_{5} \mathrm{H}_{4}$, as the numerous other oils of which oil of turpentine is the type, together with a small quantity of one or more oxygenated oils. The affinity which this grass oil has for oxygen appears to be very considerable; for even after being purified, the carburetted hydrogen part of the oil cannot be distilled without a little of it being converted into a resin. The resinous matter, of which the oil contains such a large quantity, is, I should think, therefore most probably the effect of oxidation.

XXXIII. Observations on the Pharmaceutical and Chemical Characters of the Peruvian Matico. By JoHn F. Hodges, M.D.*

A BOUT five years ago I received a parcel of the leaves of $A$ the Matico from a friend who had resided many years in Peru. He informed me that they were universally regarded by the native practitioners of that country as a most valuable remedy in various diseases, and also related several marvellous stories, current among the Indians and European settlers, of their power in arresting the most violent hæmorrhages, particularly those connected with the bladder and urinary organs. At the time I made a few experiments with the leaves, which however I was only lately able to pursue, and as they have not been subjected, so far as I can in this remote district ascertain, to a careful chemical examination either in this country or on the continent, the following observations may be interesting. It is, I believe, to Dr. Jeffreys of Liverpocl that we are indebted for the first notice in this country of the medicinal virtues of the Matico. Its action, when applied externally as a styptic, has been established in the practice of Dr. Munro of Dundee, and Dr. Lane of Lancaster has also lately communicated the results of his experience regarding its internal administration, which are confirmatory of its South American reputation. On the continent, a short notice of it has appeared in the Pharmaceutische Central Blatt, Jan. 1843, by Dr. Martius, and a brief and imperfect account of it is also given in the Dictionnaire of Merat and Lenz. It is stated by Dr. Martius, that like the Gunjah, which the East Indian prepares from the Cannabis Indica, the leaves and flowers of the Matico have been long employed by the sensual Indians of the interior of Peru to prepare a drink which they administer to produce a state of aphrodisia. 1844.

- Communicated by the Chemical Society; having been read April 1, 
The sample of Matico which I received consisted of the leaves of the plant, which were of various sizes, from two to eight inches long, and appeared to have been dried, as they could easily be rubbed to powder between the hands. It is indeed stated by Dr. Martius, that the Indians dry the leaves over a fire, taking care not to allow them to be touched by the flame or burnt. Another sample which I lately procured had the same appearance, but contained, mixed up with the leaves, a considerable quantity of the flowering twigs and woody stems of the plant. The leaves and twigs were compressed together and flattened into a cake.

The botanical history of the Matico appears to be but imperfectly known; and there exists a difference of opinion even as to the class of plants from which it is derived; Dr. Martius, in the Phar. Central Blatt, considering it to belong to the Phlomis tribe, while in the Flora Peruviana it is described as a Piper. By immersing a specimen of the plant, which seemed tolerably perfect, in warm water, I was able to examine it with considerable accuracy, and certainly its characters appear very unlike those which belong to the Phlomis family. The stems are woody, round and pubescent; the leaves sessile, acuminato-lanceolate, rugose and crenate, their upper surface of a dark green, and their lower of a pale green colour. It is said that the name of the plant is derived from a Spanish soldier named Matico, who, lying desperately wounded and bleeding to death, in his agony caught accidentally some of its leaves, and by their application arrested the hæmorrhage and healed the wound. The leaves have a strong aromatic, slightly astringent taste, and the smell and taste of their infusion in water very much resembles that of the tea prepared by the country people in Ireland from the leaves of our indigenous Salvia verbenaca.

The following experiments were undertaken to ascertain the pharmaceutical characters of the leaves.

Experiment 1.-Reduced half an ounce of the leaves to a coarse powder and macerated in six fluid ounces of cold distilled water. In ten minutes the liquid had a pale amber colour and the specific gravity 1.003; in thirty minutes its density had increased to $1 \cdot 004$ and its colour had become of a deeper amber; it possessed the peculiar aromatic astringent taste of the leaves. In two hours the liquid had specific gravity 1.005 , gave a deep olive precipitate with tinct. ferri muriat., and a yellow white with acetate of lead; tartrate of antimony produced no change. In three hours its colour was rather more brown, specific gravity $1 \cdot 005$. In five hours specific gravity $1.005 \frac{1}{2}$; when dropped into a solution of gelatine 


\section{Dr. Hodges on the Pharmaceutical and Chemical}

it produced no change. In seven hours specific gravity had not increased. In nine hours no change. The maceration having been continued for twelve hours longer, the density was not increased. The filtered liquid had a rich orange brown colour, was neutral to litmus, and possessed the smell and taste of the leaves. The following reagents were applied. Solution of gelatine, tartar-emetic, and perchloride of mercury produced no change.

Tinct. ferri muriat. $\left\{\begin{array}{c}\text { Deep black colouring and dark olive } \\ \text { precipitate. }\end{array}\right.$ Acetate of lead . . T Copious

Infusion of nutgalls $\}$ Copious canary yellow precipitates.

Sulphuric acid .

Nitric acid . . . Brown-yellow precipitates.

Muriatic acid . .

Caustic potash deepened its colour without throwing down a precipitate. Returned the liquid to the leaves and added 6 oz. cold distilled water, which reduced its specific gravity to 1.003. In three hours its density had not increased; poured off the liquid without expression and macerated the same leaves in 6 oz. cold water. In three hours the liquid had a light yellow colour and specific gravity 1.002; gave a very minute deposit with acetate of lead. Poured off the liquid and macerated for fourteen hours in the same quantity of water; specific gravity $1 \cdot 000$.

Experiment 2.-Infused half an ounce of the sub-pulverized leaves in $6 \mathrm{oz}$. boiling water. In three hours the liquid had the same taste and colour, and exhibited the same reactions as the cold infusion; specific gravity 1.006 .

Experiment 3.-Exhausted $1 \frac{1}{2}$ oz. of the leaves by boiling with distilled water over a water-bath and evaporating the filtered decoction to the consistence of an extract. The quantity of extract procured weighed 120 grains. It had a dark brown colour and bitter astringent taste, and possessed very little of the aromatic qualities of the leaves.

Experiment 4.- Introduced $3 \mathrm{oz}$. of the Matico leaves on a perforated metal support into a tin plate still with about two quarts of water and heated over the fire of a table furnace, adding fresh water occasionally to supply the loss. A milky liquid was given off possessing a strong aromatic camphoric odour, and tasting something like a mixture of oil of rosemary and oil of cubebs. It contained a considerable quantity of heavy oil of a light green colour, which slowly subsided to the bottom of the recipient. By returning the milky liquid to the still and distilling again with $2 \mathrm{oz}$, of fresh leaves, a liquid 
was procured from which about one drachm of this oil subsided.

The Oil of Matico has a light green colour; when recent it has nearly the consistence of good castor oil, but becomes thick and crystalline on keeping. Its smell is very powerful and permanent, and its strong camphoric taste remains a considerable time in the mouth. It dissolves readily in æther and in alcobol; the solutions are colourless. Sulphuric acid also dissolves it with the production of a beautiful carmine colour; water added to this solution destroys its colour and converts it into a milky liquid. Nitric acid when poured on the oil becomes of a deep amber colour, and converts it into a resinous matter. Neither caustic potash nor ammonia had any action on it. After all the oil had been separated by distillation, a deep rich red-brown liquid remained in the still; it had a bitter astringent taste, without any of the aromatic flavour of the leaves; it was neutral to litmus; the leaves were quite insipid. The filtered liquid acted towards reagents like the infusion (Exp. 1).

Experiment 5.-Added acetate of lead in excess to the filtered decoction (Exp. 4). A light olive precipitate was thrown down and separated by the filter, the excess of lead was removed by sulphuretted hydrogen from the filtered liquid, which after this treatment had a light yellow colour, and produced, with tinct. ferri muriat., merely a slight olive troubling Ammonia gave a canary-yellow precipitate, and fresh infusion of nutgalls a light brown precipitate. Evaporated over the water-bath, a gelatinous extract of the colour and appearance of thin glue remained. It tasted like the extract of Matico (Exp. 3), dissolved slowly in water, but was not acted on by xther or solution of potash. From its solution in water alcohol threw down a yray-coloured precipitate, acetate of lead ditto; perchloride of iron produced no change; caustic potash and ammonia rendered the solution orange, and threw down rich yellow precipitates. Neither muriatic acid, nitric acid or tartar-emetic produced any change. The gelatinous extract was dissolved in distilled water, the solution was cautiously evaporated over the water-bath to the consistence of a syrup, which was placed aside in a cool place, and after some hours a number of distinct prismatic crystals had formed in it. These crystals had a brown colour and cooling taste; heated on a slip of platinum foil, they decrepitated and left a yellowish white residue, which effervesced with hydrochloric acid. In their solution in water chloride of platinum threw down a yellow precipitate. Digested the syrupy extract and crystals in alcohol of $84^{\circ}$ (Gay-Lussac), its brown colour changed to 
a clear orange, and the salts collected into a gritty cake. Upon evaporating the filtered alcoholic solution, a yellowishbrown extractive matter, maticine, remained. It had a disagreeable smell and exceedingly bitter taste, like aloes, which remained a long time on the palate; it attracted moisture from the atmosphere, dissolved readily in alcohol and in water, but was not acted on by ather : heated on platinum foil it became brown, swelled up without decrepitation, and left a bulky charcoal. Its solution in water was not affected by chloride of platinum, but gave a yellow precipitate with solution of potash, and also with ammonia : chloride of barium did not alter its colour; tinct. ferri muriat. rendered it of a deep rich oarmine colour, but did not form a precipitate.

Experiment 6. - A tincture was made by macerating half an ounce of the leaves, reduced to a coarse powder, with 4 fluid ounces of alcohol of $84^{\circ}$. In half an hour the liquid had a light green colour; after macerating for six days the filtered tincture had a fine brownish-green colour, and the specific gravity $\mathbf{0} 860$. It possessed in perfection the aromatic astringent taste of the leaves; water made it muddy but occasioned no precipitate; tinct. ferri muriat. gave a copious brown black, and acetate of lead a greenish yellow precipitate; solution of potash rendered its colour deep orange, and threw down a deep orange precipitate ; ammonia produced a yellow precipitate.

Experiment 7.-The leaves were incinerated and gave 15 per cent. of a light gray ash, which contained the usual ash constituents. I am at the present time engaged with their quantitative examination, after the excellent method of Hertwig, Annal d. Chemie und Pharmacie, xlvi. Bds. $1 \mathrm{Heft.}$

Experiment 8.-When a portion of the leaves from which all the parts soluble in water had been separated was treated with æether and afterwards with alcohol, chlorophylle and a dark green resin were procured. The resinous matter was heavier than water, adhered to the fingers with great tenacity, and when heated on platinum foil burned with a strong odour of empyreumatic oil, leaving a bulky charcoal.

From the preceding experiments we may conclude that the leaves of the Matico contain the following constituents :-

1. Chlorophylle.

2. A soft dark green resin.

3. A brown colouring matter.

4. A yellow colouring matter.

5. Gum and nitrate of potash.

6. A bitter principle, maticine.

7. An aromatic volatile oil. 
8. Salts,

9. Lignin.

The leaves of the Matico are easily reduced to a fine powder, which has the colour of powdered senna; when mixed with any thick vehicle, as syrup, \&c., it presents an excellent mode of administering them, though, as will be evident, only adapted for extemporaneous prescription, as the essential oil, upon which it is probable much of their medicinal effect depends, would be rapidly dissipated by keeping. The cold infusion (Exp. 1), as it extracts all the active principles contained in the plant, seems the best form for obtaining its medicinal properties. The time required for its preparation need not exceed four hours, as in that time water extracts all that can be taken up by a single maceration, and but little is gained by maceration in fresh water, even though continued for a considerable time, as the liquid rapidly acquires its maximum density.

XXXIV. On Euclid's Trolfth Axiom. By X. Y.

To the Editors of the Philosophical Magazine and Journal. Gentlemen,

I $\mathrm{N}$ addition to the innumerable attempts which have so often been made to demonstrate the twelfth axiom of Euclid, one of a novel description has been given by Mr. Meikle in Jameson's Journal for A pril last. For this purpose, he proves, 1 st, that triangles, the areas of which are equal, have the sums of their angles equal; 2ndly, that if in one triangle the sum of the angles differed from two right angles, so it would in every triangle, and the difference would always be proportional to the area. 'Thus far the process is liable to no objection; and if it be granted that there is no triangle which can have the sum of its angles inappreciably small, his third step or inference from the second would be a complete reductio ad absurdum, viz. that a triangle of a certain magnitude would have its angles either negative, or some two of them amounting to at least two right angles.

It will now be for mathematicians to decide on the dorbtful point just stated; but at any rate the first and second propositions will form, as it were, two new instruments wherewith to perfect the theory of parallel lines. Mr. M. has shown that they are fatal to the celebrated demonstration of Bertrand; in which, besides, it is laid down as self-evident that any angle, however minute, may be multiplied to exceed any given angle. This is nearly the same with what is employed by Mr. Meikle, as noticed above. 